\title{
Development and Characterisation of Gastroretentive Solid Dosage Form Based on Melt Foaming
}

\author{
Gábor Vasvári, ${ }^{1,6}$ Ádám Haimhoffer, ${ }^{1}$ László Horváth, ${ }^{2}$ István Budai, ${ }^{3}$ György Trencsényi, ${ }^{4}$ Monika Béresová, \\ Csaba Dobó-Nagy, ${ }^{5}$ Judit Váradi, ${ }^{1}$ Ildikó Bácskay, ${ }^{1}$ Zoltán Ujhelyi, ${ }^{1}{ }^{1}$ Pálma Fehér, ${ }^{1}$ Dávid Sinka, ${ }^{1}$ \\ Miklós Vecsernyés, ${ }^{1}$ and Ferenc Fenyvesi ${ }^{1}$
}

Received 13 May 2019; accepted 1 August 2019; published online 19 August 2019

Abstract. Dosage forms with increased gastric residence time are promising tools to
increase bioavailability of drugs with narrow absorption window. Low-density floating
formulations could avoid gastric emptying; therefore, sustained drug release can be achieved.
Our aim was to develop a new technology to produce low-density floating formulations by
melt foaming. Excipients were selected carefully, with the criteria of low gastric irritation,
melting range below $70^{\circ} \mathrm{C}$ and well-known use in oral drug formulations. PEG 4000 , Labrasol
and stearic acid type 50 were used to create metronidazole dispersion which was foamed by
air on atmospheric pressure using in-house developed apparatus at $53^{\circ} \mathrm{C}$. Stearic acid was
necessary to improve the foamability of the molten dispersion. Additionally, it reduced
matrix erosion, thus prolonging drug dissolution and preserving hardness of the moulded
foam. Labrasol as a liquid solubiliser can be used to increase drug release rate and drug
solubility. Based on the SEM images, metronidazole in the molten foam remained in
crystalline form. MicroCT scans with the electron microscopic images revealed that the foam
has a closed-cell structure, where spherical voids have smooth inner wall, they are randomly
dispersed, while adjacent voids often interconnected with each other. Drug release from all
compositions followed Korsmeyer-Peppas kinetic model. Erosion of the matrix was the main
mechanism of the release of metronidazole. Texture analysis confirmed that stearic acid plays
a key role in preserving the integrity of the matrix during dissolution in acidic buffer. The
technology creates low density and solid matrix system with micronsized air-filled voids.

KEY WORDS: solid foam; lipid matrix; PEG 4000; gastric retention; solid dispersion.

\section{INTRODUCTION}

Several drugs display site-specific absorption in the gastrointestinal tract (1). Contribution of numerous factors, such as site specific, environmental $\mathrm{pH}$ and/or intestinal enzyme activity, could lead to low bioavailability (2). The gastrointestinal motility determines the residence time of the formulation in its absorption window (3).

\footnotetext{
${ }^{1}$ Department of Pharmaceutical Technology, University of Debrecen, Nagyerdei krt. 98., Debrecen, H-4032, Hungary.

${ }^{2}$ Department of Pharmaceutical Surveillance and Economics, University of Debrecen, Nagyerdei krt. 98., Debrecen, H-4032, Hungary.

${ }^{3}$ Faculty of Engineering, University of Debrecen, Ótemető utca 2-4, Debrecen, H-4028, Hungary.

${ }^{4}$ Department of Medical Imaging, University of Debrecen, Nagyerdei krt. 98., Debrecen, H-4032, Hungary.

${ }^{5}$ Department of Oral Diagnostics, Semmelweis University, Szentkirályi út 47., Budapest, H-1088, Hungary.

${ }^{6}$ To whom correspondence should be addressed. (e-mail: vasvari.gabor@pharm.unideb.hu)
}

Gastric retention is a promising mechanism for the oral modified-release drug products (4). These delivery systems provide sustained drug release coupled with resistance against the gastric milling $(5,6)$ and emptying motions $(7,8)$ and show prolonged residence time in the stomach. On the other hand, when localised therapy of the stomach or the duodenum is preferred, these delivery platforms may provide site-specific drug release for a longer time (9).

To achieve gastric retention, several technologies are available. Expanding devices increases their size upon or followed by the contact with gastric juice to inhibit transit through the pyloric sphincter. Hydrogels $(5,10)$, and other unfolding technologies, such as the Accordion Pill@ $(7,11,12)$, are formulations with prolonged residence time in the stomach. Mucoadhesive formulations containing hydrophilic polymers adhere to the gastric mucosa (13) and release their drug in sustained manner.

Floating or low-density formulations remain on the top of the gastric content (14), thus avoiding passage to the duodenum. Gas-generating platforms usually contain carbonates (15-17) and polymers to entrap the formed gas or a 
balloon filled with volatile liquid. Nevertheless, the floating lag time, the time needed for the formulation to rise to the surface, might take a couple of minutes in some cases (18). Instantly floatable devices, on the other hand, have no lag time, they remain on the surface $(9,19-21)$.

Up to date, promising new platforms and technologies to produce low density and sustained release formulations were developed. Hot-melt extrusion was successfully used to inflate extrudates with ethanol $(9)$, carbonates $(22,23)$ or pressurised carbon dioxide (24). However, these processes were done at high temperature and the cutting or spheronisation was done after filament extrusion.

Our aim was to develop a simple and new technology, based on melt-foaming, which can be easily filled into the final dosage form, namely hard gel capsules. After filling, the foam quickly solidifies upon cooling and keeps its structure. In this work, a novel apparatus is presented and detailed for foaming a molten dispersion by mechanically dispersing gas into it. The main pharmaceutical attributes of the floating solid foams are also described.

\section{MATERIALS AND METHODS}

\section{Materials}

Polyethylene glycol 4000 (PEG4000), stearic acid, type 50 (SA) and metronidazole (MNZ) were Ph. Eur. grade and purchased from Molar Chemicals Ltd. (Halásztelek, Hungary). Labrasol® was kindly gifted from Gattefossé (SaintPriest, France). Other reagents were all of analytical grade and purchased from Sigma Aldrich Kft. (Budapest, Hungary).

\section{Foaming Device Setup}

In-house apparatus was designed and built from polypropylene tube. The equipment is presented in Fig. 1. Briefly, the apparatus is a cylinder with the volume of $60 \mathrm{~mL}$, which ends at the bottom in a $10-\mathrm{mm}$ wide valve. The outer surface on the sides and at the bottom is water-jacketed with 6-mm plastic tubing. The jacket is connected to a Julabo F25 temperature control unit equipped with a Julabo $\mathrm{ME}$ circulator. The agitator is made of 1-mm wide stainless steel wires. The agitator is connected to an IKA EURO-ST D overhead stirrer. Dimensions and a schematic picture of the agitator are also presented in Fig. 1.

\section{Effect of Temperature on the Viscosity of the Molten Suspension}

The apparent viscosity of the molten PEG4000 containing $30 \mathrm{~m} / \mathrm{m} \%$ MNZ was measured by a Rheolab QC rheometer (Anton Paar Hungary Ltd.) equipped with a concentric cylinder-jacketed measuring cell. The cell was connected to a Viscoterm VT 2 waterbath (Anton Paar Hungary Ltd.). The viscosity curves were recorded with the RheoPlus software. The measurement cell was heated to $65^{\circ} \mathrm{C}$ prior to loading with the molten and homogenous MNZ suspension. Viscosities were measured between 65 and $53^{\circ} \mathrm{C}$ with the difference of $2^{\circ} \mathrm{C}$ with constant shear rate of $1000 \mathrm{rpm}$. The maximum viscosity values were plotted as a function of temperature.

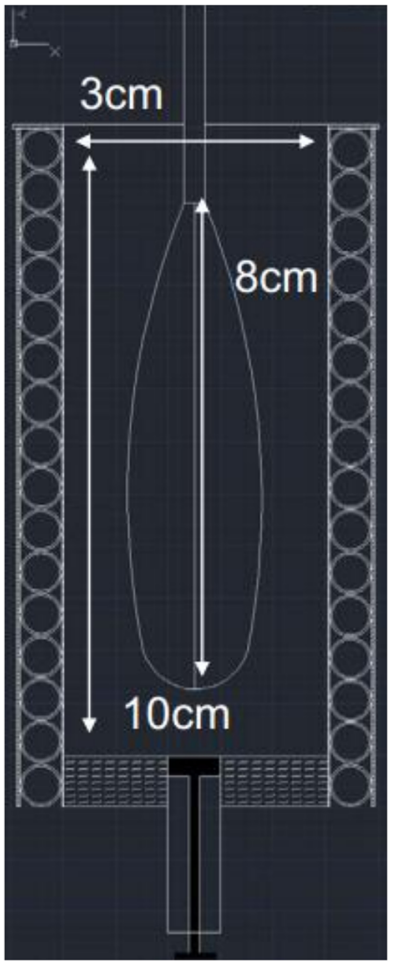

Fig. 1. In-house apparatus with a whisker-type agitator used for melting, mixing, foaming and moulding the dispersion $(3.0 \times 10.0$ diameter, height in centimetres, the difference between the shaft and the whisker head is $8.0 \mathrm{~cm}$ )

\section{Preparation of Solid Foams}

Forty grams of the different compositions (M1-M7), presented in Table I, was foamed by the following method. PEG 4000, Labrasol ${ }^{\circledR}$ and SA were measured and loaded into the preheated foaming equipment with the slow agitation of $50 \mathrm{rpm}$ at $65^{\circ} \mathrm{C}$ (jacket temperature). After complete melting, MNZ (average particle diameter, 180-125 $\mu \mathrm{m}$ ) was dispersed for $10 \mathrm{~min}$ in the molten mixture, at $300 \mathrm{rpm}$. Cooling was started by setting the temperature of the water circulating in the jacket to $53^{\circ} \mathrm{C}$. After $5 \mathrm{~min}$, when the temperature of the water reached $53^{\circ} \mathrm{C}$, foaming was done by heavy agitation at $2000 \mathrm{rpm}$ and dispersing air into the molten mass. The procedure was done for $5 \mathrm{~min}$ maximum. For further investigations of the foamed matrix system, the foamed and hot dispersion was moulded into a steel mould $(V=1.027 \mathrm{~mL}$, bullet shape) and cooled.

\section{Determination of the Densities of the Samples}

The following method was used to determine the density of the moulded compositions, (unfoamed or foamed) based on the pycnometer method. Firstly, liquid paraffin was filled into a $100-\mathrm{mL}$ volumetric flask, up to the graduation marking. The filling weight was precisely measured and the true density of liquid paraffin was calculated. The value of density was found to be $0.857 \mathrm{~g} / \mathrm{mL}$. The cavities of the steel mould were fully filled with pure PEG 4000. After scraping off the excess amount, the solid blocks were removed from the mould and their weights were recorded. Later, a sample was loaded into a $100-\mathrm{mL}$ volumetric flask and appropriate 
Table I. Compositions and Densities of the Foamed Compositions

\begin{tabular}{lllllll}
\hline Formulation & MNZ & SA & PEG 4000 & Labrasol & $\begin{array}{l}\text { Density }\left(\mathrm{g} / \mathrm{cm}^{3}\right) \pm \mathrm{SD} \\
\text { before foaming }\end{array}$ & $\begin{array}{c}\text { Density }\left(\mathrm{g} / \mathrm{cm}^{3}\right) \pm \mathrm{SD} \\
\text { after foaming }^{a}\end{array}$ \\
\hline M1 & $30 \%$ & $0 \%$ & $70 \%$ & $0 \%$ & $1.28 \pm 0.0072$ & $1.26 \pm 0.0102$ \\
M2 & $30 \%$ & $0 \%$ & $68.5 \%$ & $1.5 \%$ & $1.27 \pm 0.0073$ & $1.14 \pm 0.0195$ \\
M3 & $30 \%$ & $0 \%$ & $67.5 \%$ & $2.5 \%$ & $1.22 \pm 0.0284$ & $1.17 \pm 0.0144$ \\
M4 & $30 \%$ & $5 \%$ & $63.5 \%$ & $1.5 \%$ & $1.22 \pm 0.0178$ & $0.89 \pm 0.0341$ \\
M5 & $30 \%$ & $10 \%$ & $57.5 \%$ & $2.5 \%$ & $1.26 \pm 0.0098$ & $0.93 \pm 0.0396$ \\
M6 & $30 \%$ & $5 \%$ & $65 \%$ & $0 \%$ & $1.27 \pm 0.0093$ & $0.82 \pm 0.0261$ \\
M7 & $30 \%$ & $10 \%$ & $60 \%$ & $0 \%$ & $1.29 \pm 0.0083$ & $0.93 \pm 0.0408$ \\
\hline
\end{tabular}

Prior to density determination tests, randomly selected samples from the solidified and moulded compositions were tested to confirm instant floatation in $\mathrm{pH} 1.2$ acidic buffer. M1, M2 and M3 compositions failed on this preliminary test, and their densities were determined to be more than $1.00 \mathrm{~g} / \mathrm{cm}^{3}$

${ }^{a}$ Data present average values and standard deviations $(n=15)$

amount liquid paraffin was added to fill the flask up to $100 \mathrm{~mL}$. The volume of each sample was determined with the following formula:

$V_{s}=\frac{m_{p 1}-m_{p 2}}{\rho}$

where $V_{s}$ is the volume of the sample, $m_{\mathrm{p} 1}$ is the weight of liquid paraffin which fills up the flask without an immersed sample, $m_{\mathrm{p} 2}$ is the weight of liquid paraffin which fills up the flask with an immersed sample; $\rho$ is the density of the liquid paraffin. Using the mass and volume data of the samples, their densities were calculated.

\section{SEM Analysis and Diameter Determination of Foam Cavities}

Hitachi Tabletop microscope (TM3030 Plus) was used to characterise the solid foams (22). Samples were split in halves and were attached to a fixture with a double-sided adhesive tape containing graphite. Average diameter of the voids was calculated by measuring the diameter of hundred random cavities (GIMP 2.8 software) from at least 3 regions of the solid block.

\section{Microtomography}

In order to characterise and visualise the internal microstructure of solidified molten foamed and unfoamed dispersion of M7 samples, the following protocol was developed. As described in 'Preparation of Solid Foams' section, the regular foaming process was done. A small portion of the homogenous dispersion was removed prior to the foaming step, from the jacketed vessel with a PET tube (internal diameter, $5.0 \mathrm{~mm}$ ) attached to a $10-\mathrm{mL}$ syringe, to obtain the unfoamed sample. After the foaming step, another portion was quickly and carefully removed from the vessel with a similar PET tube to prepare the foamed sample. The molten dispersions were allowed to cool down and solidify in the plastic tubes. After solidification, the rods of the solid samples were cut into 5-6-mm long cylinders. A random foamed and unfoamed cylinder was attached to each other with a soft glue and this preparation was scanned later. A SkyScan 1272 compact desktop microCT system was used for the measurement. Scanning parameters were the following: image pixel size, $5 \mu \mathrm{m}$; matrix size, $1344 \times 2016$ (rows $\times$ columns); source voltage $=50 \mathrm{kV}$; source current $=200 \mu \mathrm{A}$; flat field correction and geometrical correction were used. After scanning, SkyScan NRecon package (Version: 2.0.4.2) was used to reconstruct cross-section images from tomography projection images. Post-alignment, Beamhardening correction, Ring artefact correction and Smoothing were done. The output formats were DICOM and BPM images.

\section{Dissolution Test}

Nine hundred milliliters of hydrochloric acid media, $\mathrm{pH}$ : 1.2 without pepsin was selected for dissolution tests $(16,25)$. Rotating paddle method with the rotation speed of $75 \mathrm{rpm}$ and $37^{\circ} \mathrm{C}$ was set up in a dissolution tester (Erweka DT 800). Samples of $4 \mathrm{~mL}$ were withdrawn after $5 \mathrm{~min}, 15 \mathrm{~min}, 30 \mathrm{~min}$, $1,2,3,4,5,6,7,8$ and $10 \mathrm{~h}$. The samples were diluted with purified water and filtered through a $0.22-\mu \mathrm{m}$ PES membrane syringe filter. The released amount of MNZ was determined by UV/VIS spectrophotometer (Shimadzu UV 1601, Shimadzu Corp. Kyoto, Japan) at $278 \mathrm{~nm}$. Three random samples were selected for the tests from every composition. Floatation was inspected at the beginning, during and at the end of the test also.

\section{Water Uptake and Matrix Erosion Studies}

Erosion and swelling properties of the solid formulations were determined by the following method. The initial weights of the samples $\left(W_{\text {ini }}\right)$ were recorded before the experiment, then they were placed into the dissolution vessels as described in the 'Dissolution Test' section. After 1, 3, 5, 7 and $10 \mathrm{~h}$, samples were carefully removed with a plastic net and the weight of the wet samples $\left(W_{\text {wet }}\right)$ was measured after blotting the excess water. The samples were then dried in an oven (Memmert SFE 550, Memmert GmbH, Germany) at $45^{\circ} \mathrm{C}$ for $48 \mathrm{~h}$, after cooling to room temperature, their constant weight $\left(W_{\text {dry }}\right)$ was measured (18). Three samples were tested from all compositions.

Water uptake \% (WU \%) was calculated by the following formula: (26)

$\% \boldsymbol{W} \boldsymbol{U}=\frac{W_{\text {wet }}-W_{\text {dry }}}{W_{\text {wet }}} \times 100$ 
Matrix erosion \% and remaining masses of the foams were determined with the following formulas (27):

$$
\begin{gathered}
\% \text { Erosion } \frac{W_{\text {ini }}-W_{\text {dry }}}{W_{\text {ini }}} \times 100 \\
\% \text { Remaining }=100 \%-\text { Erosion } \%
\end{gathered}
$$

where $W_{\text {wet }}$ means the weight of the wet samples, $W_{\text {dry }}$ means the dried weight of the samples and $W_{\text {ini }}$ means the initial weight of the samples, before test.

\section{Mathematical Analysis of the Drug Release Profiles}

To compare the dissolution data of the different compositions, similarity or difference factors were calculated, as a model independent approach: similarity, $\mathrm{f} 2$ and difference, $\mathrm{f} 1$ factor was calculated for each composition. Dissolution efficacies were also calculated (28).

$\mathrm{f} 1=\frac{\sum_{j=1}^{n}\left|R_{j}-T_{j}\right|}{\sum_{j=1}^{n} R_{j}} \times 100$

where $n$ is the sampling number, $R_{j}$ and $T_{j}$ are the percent dissolved of the reference and the test products at each time point $j$.

$$
\mathrm{f} 2=50 \times \log \left\{\left[1+(1 / n) \sum_{j=1}^{n} w_{j}\left|R_{j}-T_{j}\right|^{2}\right]^{-0,5} \times 100\right\}
$$

where $w_{j}$ is an optional weight factor.

$\mathrm{DE}=\frac{\int_{0}^{t} y \times \mathrm{d} t}{y_{100} \times t} \times 100 \%$

where $y$ is the drug percent dissolved at time $t$.

For the determination of release kinetics of MNZ, release data was fitted to zero-order, first-order and Korsmeyer-Peppas model equations.

$$
\begin{gathered}
Q=Q_{0}+k_{0} t \\
Q_{t}=Q_{0} \times e^{-k_{1} t} \\
\frac{Q_{t}}{Q_{\infty}}=k_{k p} t^{n}
\end{gathered}
$$

where $Q$ is amount of drug release at time $t, Q_{0}$ is the initial amount of drug, $Q_{t}$ is the amount of drug remaining at time $t$, and where $Q_{t} / Q_{\infty}$ is fraction of drug released at time $t . k_{0}, k_{1}$ and $k_{\mathrm{kp}}$ are the kinetic constants for zero-order, first-order and Korsmeyer-Peppas models, respectively and $n$ is the release exponent, indicative of the drug release mechanism. For Korsmeyer-Peppas model, only release data points were used in the analysis up to $60 \%$ drug release (29) .

\section{Statistical Analysis}

For statistical analysis, GraphPad Prism® (Version 6.01, GraphPad Software Inc.) was used. Unpaired $t$ tests were performed when two groups were compared, and one-way ANOVA was chosen when comparison of multiple groups was performed. Differences were considered significant at $p<0.05$ (28).

\section{Dissolution Coupled Texture Analysis}

Texture analysis was chosen to characterise the mechanical properties and structure of the dry and wetted foamed compositions. Dry samples were tested at $25^{\circ} \mathrm{C}$ without immersing them into acidic dissolution media. To monitor and determine hardness changes and erosion of the floating formulations, three random samples were placed onto dissolution vessels containing $900 \mathrm{~mL}$ of $37^{\circ} \mathrm{C} \mathrm{pH} 1.2$ hydrochloric acid media with $75-\mathrm{rpm}$ paddle speed. To visualise water permeation into the matrix, the media was coloured with 20 drops of $5 \mathrm{~m} / \mathrm{m} \%$ Sicovit ${ }^{\circledR}$ Tartrazine (BASF) solution. The samples were carefully removed after $1,3,5,7$ and $10 \mathrm{~h}$ later and excess water was removed by using soft and plastic net and tissues. Wet and dry samples were analysed by the following method. Brookfield CT3 texture analyser was equipped with an acrylic cylinder, TA25/1000, (d: $50.8 \mathrm{~mm}$ ) and the device was programmed to compress the blocks with constant speed $(0.50 \mathrm{~mm} / \mathrm{s})$ until $4500 \mathrm{~g}$ of load. At the target pressure, the device fixed the probe for $5 \mathrm{~s}$ as a hold time. Following the hold time, the probe returned to its initial position; thus, the measurement took $20 \mathrm{~s}$ per sample. The load values were plotted in the function of time (s) to present the changes in the texture in real time.

\section{RESULTS}

Effect of Temperature on the Viscosity of the Molten Suspension

Due to the polymeric nature of the PEG 4000 and to enhance the efficacy of gas entrapment in the molten dispersion, it was a key point to determine the viscositytemperature relationship of the compositions. It is known that PEG 4000 has a melting point around $58-59^{\circ} \mathrm{C}(30,31)$. On the other hand, according to the specification of the European Pharmacopoeia, the freezing range is between 53 and $59^{\circ} \mathrm{C}$. The effect of the MNZ on the viscosity changes of the solidification process was determined and the results are presented in Fig. 2. Fifty-three degree Celsius was found to show the highest viscosity values, namely 0.994 (Pa s), which was suitable for mixing. It was also noticed that during the precise cooling, the viscosity values increased as the molten dispersion became semi-solid from its liquid state. As an optimal temperature to maximise gas entrapment efficacy, $53^{\circ} \mathrm{C}$ was chosen and later foam production was done at this temperature.

\section{Density Values of the Foamed Compositions}

The density values and the average weights of the dispersions before and after foaming are also presented in Table I. It was found that M1, M2 and M3 are non-floating compositions, because their density results are higher than $1 \mathrm{~g} / \mathrm{mL}$. These compositions were excluded from further 


\section{$30 \mathrm{~m} / \mathrm{m} \%$ MNZ suspension}

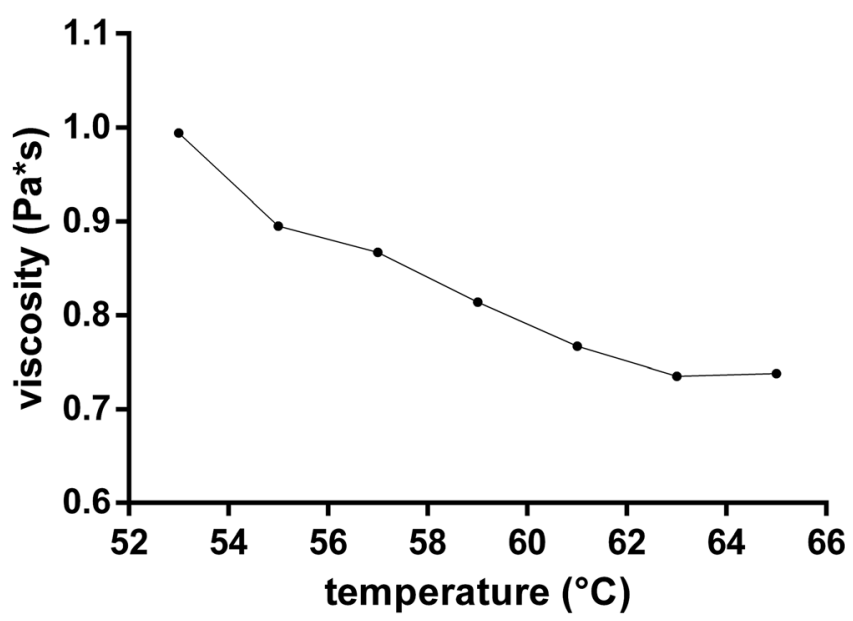

Fig. 2. Viscosity temperature curve of the $30 \mathrm{~m} / \mathrm{m} \%$ MNZ- PEG 4000 suspension

investigations. M4, M5, M6 and M7 were successfully foamed with this technology as their density values were below $1 \mathrm{~g} /$ $\mathrm{mL}$ and as a result, all of the foamed M4, M5, M6 and M7 compositions showed zero floating lag time in purified water. As a result of the foaming, the values of standard deviations increased as shown in Table I. The lowest density reached was $0.82 \mathrm{~g} / \mathrm{mL}$, this belongs to the M6 formulation. This means a $35.6 \%$ decrease in the mass, due to the dispersed gas. The average calculated API content in this formulation was found to be $252.3 \mathrm{mg}$.
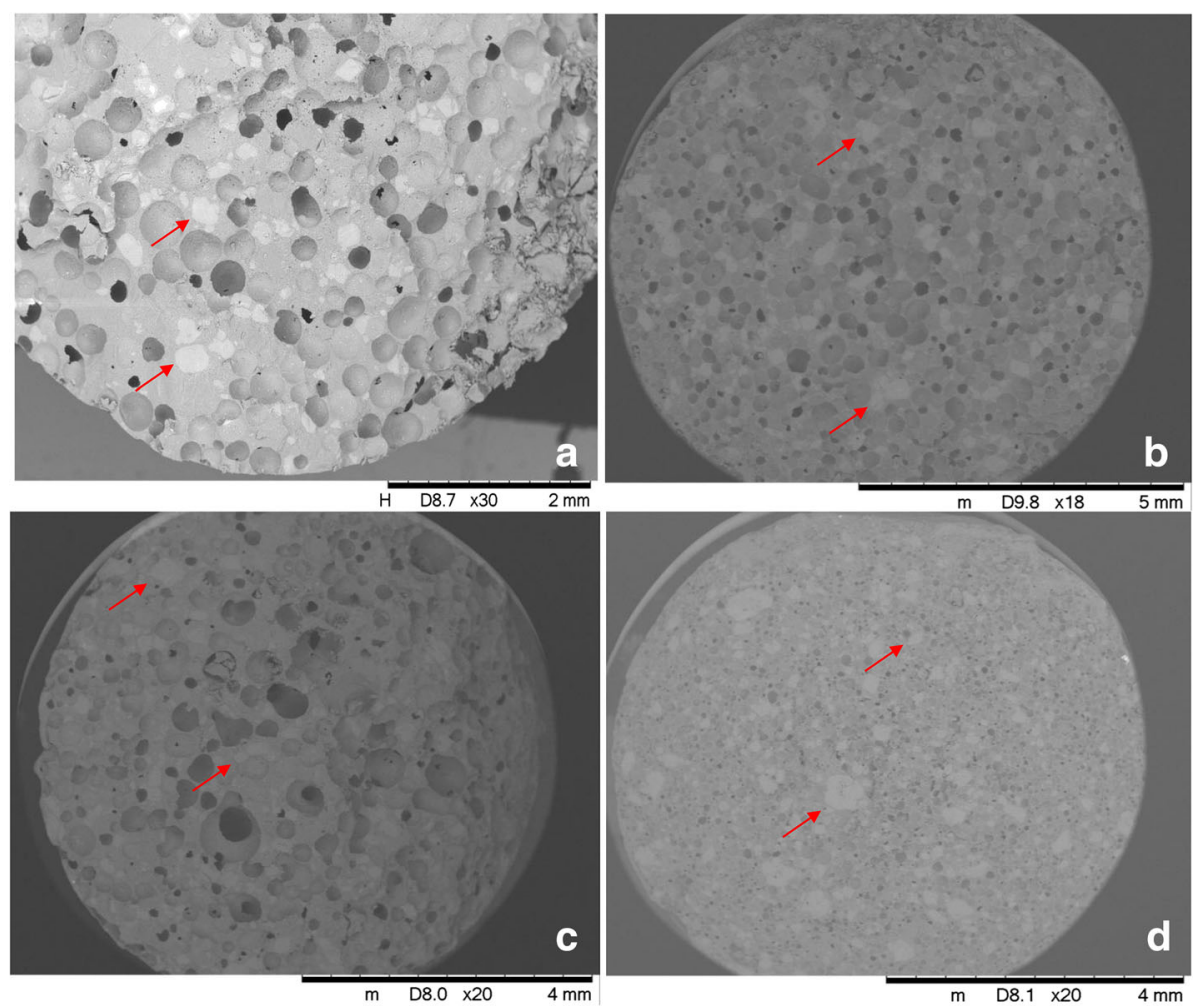

Fig. 3. Representative SEM pictures of the M4 (a), M5 (b), M6 (c) and M7 (d) solid foams. Magnifications are between $\times 18$ and $\times 30$. Red arrows indicate the solid particles of MNZ in the solid foams

\section{SEM Analysis and Void Characteristics}

On the SEM images (Fig. 3), the cavities created in the melt by the dispersed gas phase can be easily distinguished from the matrix of the solidified melt and the crystals of the MNZ are also detectable. Owing to dispersing air into the molten material, the shape of the cavities is typically spherical or spheroidal. Cavities formed by the merging of bubbles may also be present. The cavities formed by merging of bubbles have short channel-like appearance, and they are assumed to originate from mechanically dispersing gas in the melt. The inner surfaces of the cavities are typically smooth, uneven surface can possibly be seen as well, as a result of the solidified but once fluid melt. The solidified melt forms one single phase in which the solid, undissolved crystals of the MNZ are present and the cavities created by the dispersed gas are distributed randomly. Particles of MNZ can be easily distinguished from the melted and solidified carrier and from the cavities created by the dispersed gas. It is not typical that any of the interfaces in the melt is enriched in solid particles. Scanning electron microscopy confirmed the development of a closed cell foam structure in the case of all foamed compositions. The structure of the foam is homogeneous and the smooth outer surface does not form a shell. The sizes of the voids were found to be $254 \pm 83,193 \pm 63$, $231 \pm 113$ and $67 \pm 25 \mu \mathrm{m}$ for M4; M5; M6 and M7, respectively.

\section{Microtomography Results}

Figure 4 shows the reconstructed image of the microCT scans performed on M7 composition. It is clearly seen that the 
process phase of MNZ dispersion incorporates tiny air bubbles into the molten dispersion which form voids in the molten matrix thereafter. On the other hand, the foaming process step creates a highly porous structure where the molten matrix is loaded with spherical or spheroidal bubbles. The distribution of the bubbles or voids is random. The reconstructed and computed model of the foam structure shows a closed cell structure in which interconnecting voids or deformed bubbles are present. These short channel-like voids could show various shapes, but most of them can be imagined as few chambers or rooms interconnected with tubular passages. However, none of them were found to be opened to the outer environment.

\section{Dissolution and Floating Properties}

During the dissolution tests, all samples were proven to possess zero floating lag time and none of them sank before complete disintegration. In the case of completely disintegrated M4 compositions, raft-like remnants were

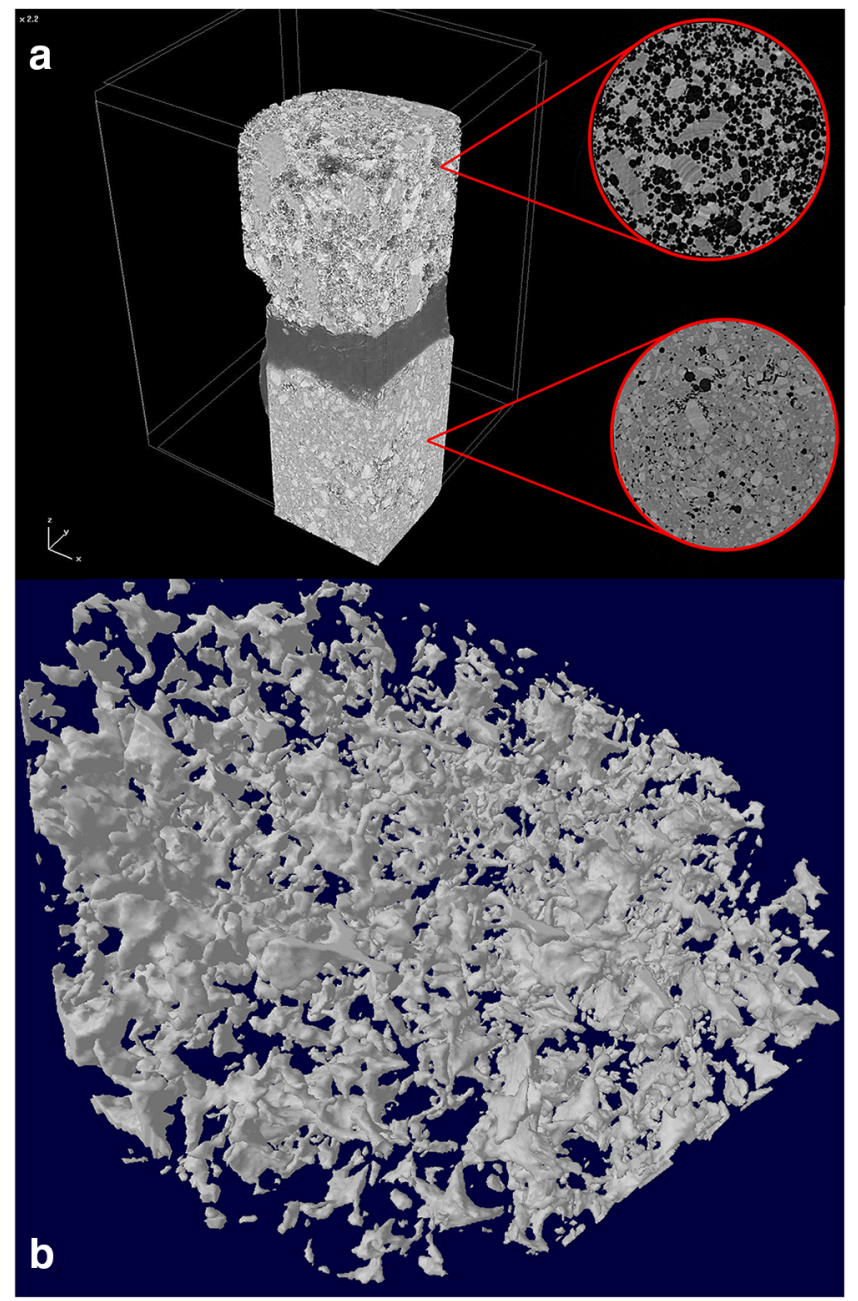

Fig. 4. a Reconstructed microCT image of the M7 composition. The upper block represents the foamed product with a section from the original images, while the lower block represents the unfoamed product with a section from the original images. b Reconstructed model of the foamed melt presenting a closed-cell structure with interconnecting voids present at the top of the aqueous media. Dissolution properties (dissolution profile, results of the water uptake studies along with the erosion of the formulations) are presented in Fig. 5. M4 was found to release the MNZ in the shortest time, namely $91.07 \%$ were dissolved until $3 \mathrm{~h}$. Water uptake curve of M4 greatly differs from the others. It was observed that the percentage of the water uptake of this formulation increased until $1 \mathrm{~h}$, then a maximum uptake was reached at $3 \mathrm{~h}$. At this time point, one of the samples completely eroded, and only two were removed and tested. The average of the percentage of remaining mass of the samples is only $6.56 \%$. After $7 \mathrm{~h}$, complete disintegration of the foamed matrix of M4 occurred. M5 released $88.33 \%$ of the drug after $5 \mathrm{~h}$. Regarding its water uptakes and erosion, only $15.16 \%$ of the original mass of M5 was found in the dissolution media, with absorbing $68.97 \%$ water from the dissolution buffer. Water uptake maximums were found at 10 h, namely $82.16 \%, 86.95 \%$ and $69.94 \%$ for M5, M6 and
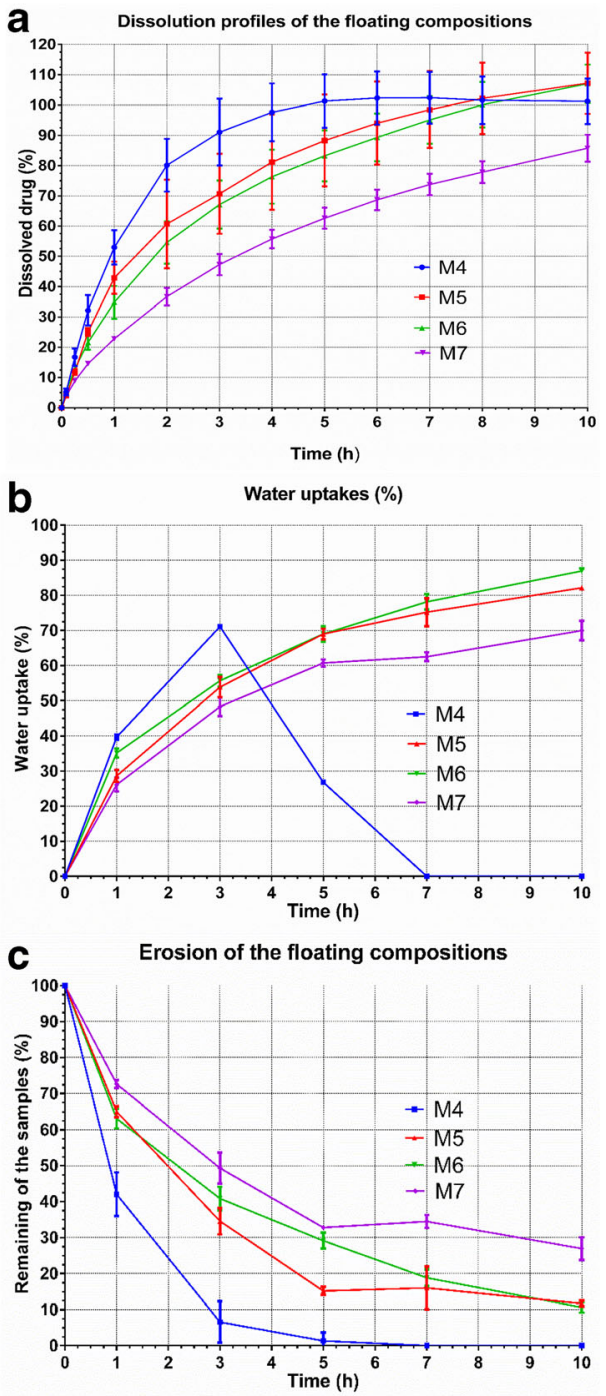

Fig. 5. a Dissolution profiles of the floating foamed compositions. Bars represent mean \pm S.D. $(n=3)$. b Water uptake (\%) vs. time (h) curves of the floating foamed compositions. Bars represent mean \pm S.D. $(n=3)$. c Erosion of the floating foamed compositions. Bars represent mean \pm S.D. $(n=3)$ 
M7, respectively. M6 released only $83.27 \%$ at $5 \mathrm{~h}$, at that time point, $29.13 \%$ of the average initial weight was present in the dissolution vessel. Water uptake of the M6 samples continuously increased by time until the end of the test. M7 was found to release only $85.79 \%$ its MNZ content at $10 \mathrm{~h}$. M7 adsorbed the least amount of water during this test and showed that the average of $26.92 \%$ mass remained after $10 \mathrm{~h}$.

\section{Drug Release Analysis and Model Fitting}

Dissolution efficiencies were calculated for each floating compositions and are presented along with the results of the pairwise procedure analysis in Table II. Comparison of the release profiles revealed that the drug release from M5 and M6 can be considered similar only (f1 and f2 are 4.92 and 67.87, respectively). When the dissolution efficiencies were calculated, it was found that for M4 showed the fastest release with the value of $88.43 \%$, while for $\mathrm{M} 7$, the value of DE was only $57.21 \%$.

Drug release data were fitted to zero-order, first-order and Korsmeyer-Peppas models (Table III). Determination coefficients were used to determine the best fit. None of the models fitted to zero-order model, while the calculations revealed that the release data of all presented formulations fitted best to the Korsmeyer-Peppas model, since the correlation coefficients were all greater than 0.99 .

\section{Texture Analysis}

Figure 6 represents the results of the texture analysis. It was revealed that in the cases of all floating compositions, a hard and resistant structure is present in spite of the air entrapment. Applying $4500 \mathrm{~g}$ of compression load on the foams did not result any cracks or fractures in the dry state at $25^{\circ} \mathrm{C}$. On the other hand, when the compositions were compared, it was found that the deformation of M4 under the constant pressure of the analyser probe for $5 \mathrm{~s}$ is significantly different that the others, $p<0.0001$. Regarding M4, a softer structure was found. As was expected on the basis of the erosion studies, M4 samples could be tested at only $1 \mathrm{~h}$. M4 samples presented small dry and resistant cores inside, the compression of this core resulted a sharp drop in the load values, as seen on the diagram at $6.54 \mathrm{~s}$ (Fig. 6b). Those inner cores in the three parallel samples were small and fragile enough to be compressed and flattened by the

Table II. Release Profile Comparison and Dissolution Efficiencies of the Floating Formulations

Dissolution efficiencies Pair-wise comparison of dissolution profiles

\begin{tabular}{lllll} 
& & & $\mathrm{f1}^{a}$ & $\mathrm{f} 2^{b}$ \\
\hline & & M4 vs M5 & 11.11 & 47.28 \\
& & M4 vs M6 & 15.48 & 41.06 \\
M4 & $88.43 \%$ & M4 vs M7 & 36.88 & 25.84 \\
M5 & $79.84 \%$ & M5 vs M6 & 4.92 & 67.87 \\
M6 & $76.04 \%$ & M5 vs M7 & 28.99 & 33.92 \\
M7 & $57.21 \%$ & M6 vs M7 & 25.32 & 38.02 \\
\hline
\end{tabular}

${ }^{a}$ f1 values of the difference factor calculation

${ }^{b} \mathrm{f} 2$ values of the similarity factor calculation moving probe. M5, M6 and M7 still contained dry, solid cores inside also, but their resistance against the compression force was different. When the M5 samples were tested, two of them contained dry cores resistant to the compression force, but one of them contained a fragile core inside which collapsed under the pressure of $3609 \mathrm{~g}$ and a series of smaller collapses took place until a more compacted structure developed to stop the measurement probe. M6 showed an outer pliable and deformable jacket-like outer part, compared with M7. M7 however presented a wetted outer layer which separated duo to the compressional test (Fig. 6d). After $3 \mathrm{~h}$, all samples of M5, M6 and M7 were compressed and somewhat flattened by the measurement probe. M5 samples showed fragile inner cores which collapsed with a series of smaller collapses upon compression. The upslope of the curve starts at earlier time point, namely at $6.84 \mathrm{~s}$ indicating that the M5 compared with M6 (upslope starts at $8.92 \mathrm{~s}$ ) and M7 has a softer structure. M7 at this time point also showed a more solid structure, since the load values are higher even at early time points, from 2 to $7 \mathrm{~s}$. On the other hand, as represented with a photo on Fig. 6d, M7 lost a much of its integrity compared with the 1-h measurement. After $5 \mathrm{~h}, \mathrm{M} 7$ contained only dry and brittle core, and from 2 to $11 \mathrm{~s}$ of the test time, higher load values were recorded. After $7 \mathrm{~h}$, a nearly complete wetting and erosion of the samples resulted similar load-time curves for M5, M6 and M7. The only difference was found in the time coordinates of the turning points, namely 9.30, 10.18 and 12.20 for M5, M6 and M7, respectively.

\section{DISCUSSION}

Our aim in this study was to design, build and use a batch type in-house apparatus to produce lipid-based monolithic matrices. We created low density, sustained release formulations with instant floating properties in acidic buffer without the need of gas generation and entrapment. After foaming, the formulation can be easily filled into the final dosage form, hard gel capsules, and then the foam quickly solidifies upon cooling and keeps its structure resulting the floating properties.

For the selection of the appropriate materials, we considered the following. The main matrix component must be solid at body temperature; therefore, it should possess mechanical resistance against the churning movements of the gastric contraction waves, because early matrix disintegration will lead to faster drug release (32). On the other hand, it should melt below $70^{\circ} \mathrm{C}$, this temperature is a key factor. This temperature is the maximum filling temperature of hard gelatine capsules. At lower temperature, no risk of capsule

Table III. Model Fitting Results of the Dissolution Data

\begin{tabular}{llll}
\hline Composition & Zero-order & First-order & Korsmeyer-Peppas \\
\hline M4 & 0.7038 & 0.9875 & 0.9932 \\
M5 & 0.7148 & 0.9479 & 0.9967 \\
M6 & 0.7790 & 0.9836 & 0.9989 \\
M7 & 0.8324 & 0.9947 & 0.9985 \\
\hline
\end{tabular}

All values represent determination coefficients for each model fittings. Italic numbers indicate the highest values for each composition 

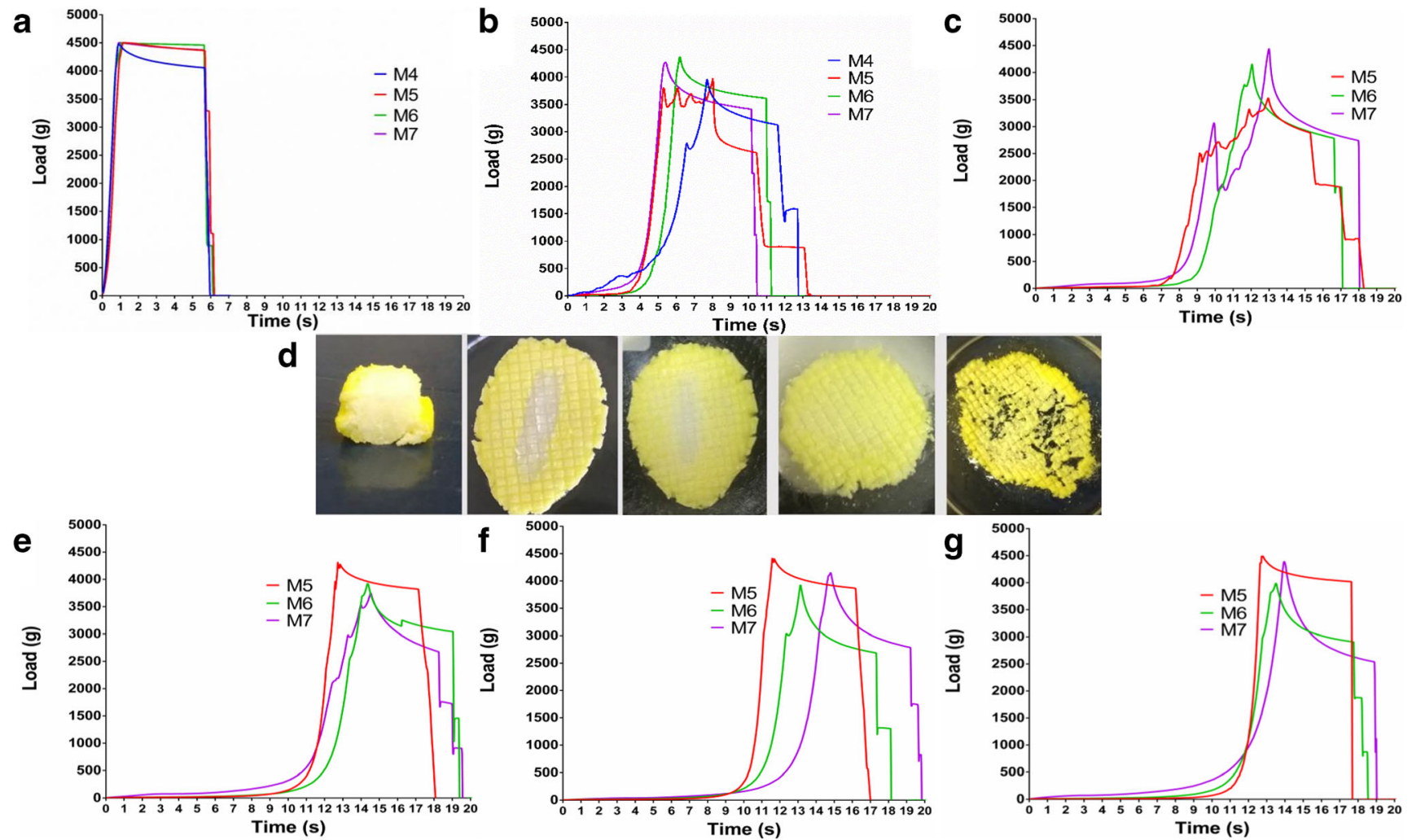

Fig. 6. a Texture analysis result of the dry, foamed compositions at $25^{\circ} \mathrm{C}$ and dissolution coupled texture analysis result of the immersed samples at $37^{\circ} \mathrm{C}$ after $1 \mathrm{~h} \mathrm{(b),} 3 \mathrm{~h} \mathrm{(c),} 5 \mathrm{~h}(\mathbf{e}), 7 \mathrm{~h}(\mathbf{f}), 10 \mathrm{~h}(\mathbf{g})$. d Representative photos of M7 solid foams after compression by the measurement probe (from left to right: 1, 3, 5, 7 and $10 \mathrm{~h}$ ), yellow stain was added into the dissolution media to follow the water permeation into the sample

shell damage (33) can occur and this attribute provides the possibility that the foamed dispersion can be filled into twopiece hard gel capsules. During our study, we applied a steel mould to study the foamed matrices and to discover its main pharmacological and physicochemical properties. The volume of each cavity in the mould $(1.027 \mathrm{~mL})$ and their dimensions are comparable with size 00 hard capsule $(0.91 \mathrm{~mL})$. Gastroretentive formulations must remain in the stomach to gradually release the API, which can be absorbed through the proximal part of the small intestine later $(2,9)$. However, accumulation of the empty carriers should not happen; therefore, degradability or gradual disintegration (34) must be integrated into the matrix by careful design. PEGs, for instance PEG 4000, are a polymer with high degree of solubility in water and a melting range below $60^{\circ} \mathrm{C}$. It is also favourable from technological aspect that it can exist in semisolid state also, in which state, due to the high viscosity (35), dispersing gas into the fluid dispersion leads to a more efficient foam formation. Optimal temperature with sufficient ability to be moulded and to entrap gas was found for this polymer at $53^{\circ} \mathrm{C}$.

In this study, we demonstrate that four different compositions with zero floating lag time were prepared with our apparatus in batch mode by filling the foamed and hot dispersions into metal mould. Labrasol for our experiments were selected as a non-ionic oil-in-water surfactant. In spite of its HLB value of 14 , it has a decreased cytotoxicity compared with Polysorbates (36). It is well known as a solubiliser and o/ w surfactant. It can be used for microemulsions and it is able to form light foams, as well (37). Based on our result, we can state that to sufficiently decrease the density of the dispersions, at least $5 \%$ SA was also elementary, $1.5 \%$ or $2.5 \mathrm{~m} / \mathrm{m} \%$ Labrasol alone could not decrease the densities below the density limit of $1.00 \mathrm{~g} / \mathrm{mL}$. However, we do not exclude the possibility that with increased agitation speed and shear force coupled with controlled gas injection, PEG-API gas dispersions can be created. Our apparatus disperse air at atmospheric pressure into the molten dispersion by cavitation and by vortex formation. During operation the wires of the agitator leaving and splashing into the swirling dispersion (38), this mechanism sucks and pulls air into the liquid in motion by breaking up the gas/liquid interface and also cause breakup of the previously dispersed bubbles. Addition of $5 \mathrm{~m} /$ $\mathrm{m} \% \mathrm{SA}$ to the PEG-MNZ dispersion decreased the density to the average value of $0.82 \mathrm{~g} / \mathrm{mL}$. This was a surprising and an unexpected result for us, which highlighted the importance of this material. The HLB value of the SA is 15 (39).

Besides its numerous application as a dissolution retardant (40) in oral hydrophobic matrix systems, SA when neutralised with tetrabutylammonium hydroxide can be used to create foam from o/w emulsions (41). The authors states based on the results of the experiments that SA contributes to the easier foamability due to two of its property. Firstly, SA, type 50 contains not only pure C18 fatty acid, this type of the excipient should contain at least $40.0-60.0 \%$ stearic acid, and the sum of the stearic acid and palmitic acid content must be at least $90.0 \%$. The palmitic acid content results a lower melting temperature range, namely between 53 and $59^{\circ} \mathrm{C}$ compared with the pure SA, melting point, $69 \cdot 6^{\circ} \mathrm{C}(39,42)$. This contributes to an increased viscosity at $53^{\circ} \mathrm{C}$. Secondly, 
the presence of $\mathrm{C} 18$ and $\mathrm{C} 16$ fatty acids in the PEG matrix could also stabilise the air/PEG interface by accumulating at the surface of the air bubbles, thus creating an apolar layer which surrounds the dispersed gas phase. Similar mechanism has been earlier described and discussed when diary emulsion was foamed with a similar whipping technique $(43,44)$. This hypothesis however should be confirmed by upcoming experiments.

The stabilization of the air/PEG interface can be detected when surface analysis was performed, adding SA alone results air bubbles in micron scale, while combining Labrasol with SA results an increase in the void sizes. On the other hand, open-cell structures were not created, but short and interconnecting clusters of spherical voids developed in all cases. None of the pictures showed that the dispersed crystals of MNZ were involved in bubble entrapment of interphase stabilisation, this is in concordance with the data of M1 composition presented in Table I. MicroCT scans on M7 foam structure confirmed a presence of a complex spongy structure. The foam structure however is not surrounded by a hard and thick, bubble-free shell-layer or outer jacket. Air was randomly distributed throughout the whole matrix. Signs of bubble coalescence, on the other hand, were detected. It can be stated on the basis of the results of imaging techniques, on Fig. 3 a, b and c, the interconnections are clearly seen on SEM pictures, while microCT scan of M7 confirmed the same structure with smaller voids (Fig. 4). SEM pictures also confirmed that MNZ remained in its crystalline form. Additionally, MNZ melts at $162.32^{\circ} \mathrm{C}$ (28), and no solid solution was prepared.

When the foamed compositions were investigated regarding their release characteristics, we found that the Labrasol increased the erosion and dissolution rates due to its good ability of micelle solubilisation (36). Regarding the water uptake studies, the PEG matrix absorbs water and swelling of the polymer chains develops; however, we should also mention that water can also penetrate and fill up the micronsized cavities. On the other hand, the whole inner pore system could not be completely flooded due to the shortness of the interconnections. This is favourable, since gas is entrapped in separate chambers providing continuous floatation. Dissolution of MNZ when compared with the matrix erosion curve suggests that drug release is mainly controlled by erosion. It can be stated on the basis of the presence of MNZ crystals and the low solubility of MNZ in water (45). On the one hand, it is noteworthy to mention that the diffusion path of the dissolved drug is elongated since airfilled voids are impermeable for the dissolution media, on the other hand, diffusion still contributes to the release of MNZ through the flooded channels and pores (1).

Comparison of dissolution data demonstrated that the release profiles of M5 and M6 can be considered similar only (f1: 4.92 and f2: 67.87) (46) in spite of their different composition and density (Table I), as well. Kinetic model analysis revealed that Korsmeyer-Peppas model fitted best to dissolution data (Table III): This kinetic model is used to analyse drug release of polymeric formulations when more than one type of release phenomena is involved. Release exponents of M4 and M5 were 0.9414 and 0.9759 indicate Super Case-II transport due to the cylindrical shape, while for M6 and M7, the $n$ values were 0.7162 and 0.6889 corresponding to anomalous or non-Fickian diffusion transport. According to these findings, beside the rates of drug release, the mechanism is modified by Labrasol, as well. A possible explanation could be that Labrasol works as a plasticiser in the matrix; therefore, a rapid water uptake and matrix is coupled with the increased API concentration in the inner pores, due to the solubilisation of MNZ.

This also suggests differences in the speed of structural weakening of the foams as seen during texture analyses. Plasticising the PEG and SA chains together with a higher rate of water imbibition resulted the fastest erosion of M4. Plasticising effect could be the reason of the significantly softer texture of the dry $\mathrm{M} 4$ at $25^{\circ} \mathrm{C}$. However, $10 \%$ of SA was able to develop a more ordered structure, resulting a harder and more resistant matrix. SA not only delays disintegration and increases hardness, but due to its edible nature, shows advantageous properties as oral release retardant (47).

\section{CONCLUSION}

This study describes a novel technology developed to foam hot and molten dispersions on atmospheric pressure. This technology is directly applicable to produce floating, lowdensity moulded dosage forms. Undissolved drug in the molten dispersion does not affect the continuous buoyancy up to $30 \%$. MNZ was released mainly by the erosion of the PEG-SA matrix; however, Labrasol as a non-ionic solubiliser alters the dissolution mechanism by increasing drug solubility and increasing the rate of water uptake. We applied several methods to characterise the properties of foam matrix system. SEM pictures and microCT scans confirmed that air bubbles form spherical closed-cell structure where clusters of interconnecting voids can be found. Texture analysis confirmed that SA in our matrices inhibits disintegration and maintains mechanical resistance in acidic buffer at $37^{\circ} \mathrm{C}$. The temperature of the technology is ideal for hard capsule filling to prolong gastric residence time.

\section{FUNDING INFORMATION}

Open access funding provided by University of Debrecen (DE). This paper was financially supported by the János Bolyai Research Scholarship of the Hungarian Academy of sciences (BO/00290/16/5). The publication is supported by the EFOP-3.6.1-16-2016-00022 projects. The project is cofinanced by the European Union and the European Social Fund. This research was also supported by the European Union and the State of Hungary, co-financed by the European Social Fund in the framework of GINOP-2.2.1-152017-00079.

Open Access This article is distributed under the terms of the Creative Commons Attribution 4.0 International License (http://creativecommons.org/licenses/by/4.0/), which permits unrestricted use, distribution, and reproduction in any medium, provided you give appropriate credit to the original author(s) and the source, provide a link to the Creative Commons license, and indicate if changes were made.

\section{REFERENCES}

1. Svagan AJ, Benjamins JW, Al-Ansari Z, Shalom DB, Mullertz A, Wagberg L, et al. Solid cellulose nanofiber based foams towards facile design of sustained drug delivery systems. J 
Control Release. 2016;244(Pt A):74-82. https://doi.org/10.1016/ j.jconrel.2016.11.009.

2. Sandercock D, Cramer M, Biton V, Cowles VE. A gastroretentive gabapentin formulation for the treatment of painful diabetic peripheral neuropathy: efficacy and tolerability in a double-blind, randomized, controlled clinical trial. Diabetes Res Clin Pract. 2012;97(3):438-45. https://doi.org/10.1016/ j.diabres.2012.03.010.

3. Lopes CM, Bettencourt C, Rossi A, Buttini F, Barata P. Overview on gastroretentive drug delivery systems for improving drug bioavailability. Int J Pharm. 2016;510(1):144-58. https:// doi.org/10.1016/j.ijpharm.2016.05.016.

4. Khan FN, Dehghan MH. Enhanced bioavailability of atorvastatin calcium from stabilized gastric resident formulation. AAPS PharmSciTech. 2011;12(4):1077-86. https://doi.org/ 10.1208/s12249-011-9673-3.

5. Dorkoosh FA, Stokkel MPM, Blok D, Borchard G, RafieeTehrani A, Verhoef JC, et al. Feasibility study on the retention of superporous hydrogel composite polymer in the intestinal tract of man using scintigraphy. J Control Release. 2004;99(2):199-206. https://doi.org/10.1016/j.jconrel.2004.06.012.

6. Eberle VA, Schoelkopf J, Gane PAC, Alles R, Huwyler J, Puchkov M. Floating gastroretentive drug delivery systems: comparison of experimental and simulated dissolution profiles and floatation behavior. Eur J Pharm Sci. 2014;58:34-43. https:// doi.org/10.1016/j.ejps.2014,03.001.

7. LeWitt PA, Giladi N, Gurevich T, Shabtai H, Djaldetti R, Roizen N, et al. Accordion pill carbidopa/levodopa (AP-CD/ LD) for treatment of advanced PD. Movement Disord. 2014;29:S248-S.

8. Eisenacher F, Garbacz G, Mader K. Physiological relevant in vitro evaluation of polymer coats for gastroretentive floating tablets. Eur J Pharm Biopharm. 2014;88(3):778-86. https:// doi.org/10.1016/j.ejpb.2014.07.009.

9. Vo AQ, Feng X, Morott JT, Pimparade MB, Tiwari RV, Zhang $\mathrm{F}$, et al. A novel floating controlled release drug delivery system prepared by hot-melt extrusion. Eur J Pharm Biopharm. 2016;98:108-21. https://doi.org/10.1016/j.ejpb.2015.11.015.

10. Halim SAA, Yehia SA, El-Nabarawi MA. Chromium picolinate loaded superporous hydrogel and superporous hydrogel composite as a controlled release device: in vitro and in vivo evaluation. J Drug Deliv Sci Tec. 2014;24(4):326-37.

11. LeWitt PA. New levodopa therapeutic strategies. Parkinsonism Relat D. 2016;22:S37-40. https://doi.org/10.1016/j.parkreldis.2015.09.021.

12. Kagan L, Lapidot N, Afargan M, Kirmayer D, Moor E, Mardor Y, et al. Gastroretentive accordion pill: enhancement of riboflavin bioavailability in humans. J Control Release. 2006;113(3):208-15. https://doi.org/10.1016/j.jconrel.2006.03.022.

13. Rajput P, Singh D, Pathak K. Bifunctional capsular dosage form: novel fanicular cylindrical gastroretentive system of clarithromycin and immediate release granules of ranitidine HC1 for simultaneous delivery. Int J Pharm. 2014;461(1-2):31021. https://doi.org/10.1016/j.ijpharm.2013.11.053.

14. Choudhary S, Jain A, Amin MCIM, Mishra V, Agrawal GP, Kesharwani P. Stomach specific polymeric low density microballoons as a vector for extended delivery of rabeprazole and amoxicillin for treatment of peptic ulcer. Colloid Surface B. 2016;141:268-77. https://doi.org/10.1016/j.colsurfb.2016.01.048.

15. Dios P, Nagy S, Pal S, Pernecker T, Kocsis B, Budan F, et al. Preformulation studies and optimization of sodium alginate based floating drug delivery system for eradication of helicobacter pylori. Eur J Pharm Biopharm. 2015;96:196-206. https://doi.org/10.1016/j.ejpb.2015.07.020.

16. Yin LF, Qin C, Chen KS, Zhu CL, Cao H, Zhou JP, et al. Gastro-floating tablets of cephalexin: preparation and in vitro/in vivo evaluation. Int J Pharm. 2013;452(1-2):241-8. https:// doi.org/10.1016/j.ijpharm.2013.05.011.

17. Nama M, Gonugunta CSR, Veerareddy PR. Formulation and evaluation of gastroretentive dosage forms of clarithromycin. AAPS PharmSciTech. 2008;9(1):231-7. https://doi.org/10.1208/ s12249-008-9038-8.

18. Oh TO, Kim JY, Ha JM, Chi SC, Rhee YS, Park CW, et al. Preparation of highly porous gastroretentive metformin tablets using a sublimation method. Eur J Pharm Biopharm. 2013;83(3):460-7. https://doi.org/10.1016/j.ejpb.2012.11.069.
19. Sauzet C, Claeys-Bruno M, Nicolas M, Kister J, Piccerelle P, Prinderre P. An innovative floating gastro retentive dosage system: formulation and in vitro evaluation. Int J Pharm. 2009;378(1-2):239. https://doi.org/10.1016/j.ijpharm.2009.05.027.

20. Streubel A, Siepmann J, Bodmeier R. Floating matrix tablets based on low density foam powder: effects of formulation and processing parameters on drug release. Eur J Pharm Sci. 2003;18(1):37-45. https://doi.org/10.1016/S0928-0987(02)00223-3.

21. Strusi OL, Sonvico F, Bettini R, Santi P, Colombo G, Barata P, et al. Module assemblage technology for floating systems: in vitro flotation and in vivo gastro-retention. J Control Release. 2008;129(2):88-92. https://doi.org/10.1016/j.jconrel.2008.04.015.

22. Vo AQ, Feng X, Pimparade M, Ye XY, Kim DW, Martin ST, et al. Dual-mechanism gastroretentive drug delivery system loaded with an amorphous solid dispersion prepared by hotmelt extrusion. Eur J Pharm Sci. 2017;102:71-84. https://doi.org/ 10.1016/j.ejps.2017.02.040.

23. Fukuda M, Peppas NA, McGinity JW. Floating hot-melt extruded tablets for gastroretentive controlled drug release system. J Control Release. 2006;115(2):121-9. https://doi.org/ 10.1016/j.jconrel.2006.07.018.

24. E AA, Kulkarni V, Almutairy B, Park JB, Shah SP, Majumdar $\mathrm{S}$, et al. Influence of pressurized carbon dioxide on ketoprofenincorporated hot-melt extruded low molecular weight hydroxypropylcellulose. Drug Dev Ind Pharm. 2016;42(1):12330. https://doi.org/10.3109/03639045.2015.1035282.

25. Mazer N, Abisch E, Gfeller JC, Laplanche R, Bauerfeind P, Cucala $\mathrm{M}$, et al. Intragastric behavior and absorption kinetics of a normal and "floating" modified-release capsule of isradipine under fasted and fed conditions. J Pharm Sci. 1988;77(8):647-57.

26. Kreye F, Siepmann F, Willart JF, Descamps M, Siepmann J. Drug release mechanisms of cast lipid implants. Eur J Pharm Biopharm. 2011;78(3):394-400. https://doi.org/10.1016/ j.ejpb.2011.02.011.

27. Dios P, Szigeti K, Budan F, Pocsik M, Veres DS, Mathe D, et al. Influence of barium sulfate X-ray imaging contrast material on properties of floating drug delivery tablets. Eur J Pharm Sci. 2016;95:46-53. https://doi.org/10.1016/j.ejps.2016.09.034.

28. Vasvari G, Csontos B, Sovany T, Regdon G Jr, Benyei A, Varadi J, et al. Development and characterisation of modified release hard gelatin capsules, based on in situ lipid matrix formation. AAPS PharmSciTech. 2018;19:3165-76. https:// doi.org/10.1208/s12249-018-1146-5.

29. Costa P, Manuel J, Lobo S. Modeling and comparison of dissolution profiles. Eur J Pharm Sci. 2001;13(2):123-33. https://doi.org/10.1016/S0928-0987(01)00095-1.

30. Patil MP, Gaikwad NJ. Preparation and characterization of gliclazide-polyethylene glycol 4000 solid dispersions. Acta Pharma. 2009;59(1):57-65.

31. Liu CS, Desai KG. Characteristics of rofecoxib-polyethylene glycol 4000 solid dispersions and tablets based on solid dispersions. Pharm Dev Technol. 2005;10(4):467-77. https:// doi.org/10.1080/10837450500299701.

32. Schneider F, Hoppe M, Koziolek M, Weitschies W. Influence of postprandial intragastric pressures on drug release from gastroretentive dosage forms. AAPS PharmSciTech. 2018;19(7):2843-50. https://doi.org/10.1208/s12249-018-1022-3.

33. Stegemann S. Hard gelatin capsules today - and tomorrow2002.

34. Swarnakar NK, Venkatesan N, Betageri G. Critical in vitro characterization methods of lipid-based formulations for oral delivery: a comprehensive review. AAPS PharmSciTech. 2019;20(1):16. https://doi.org/10.1208/s12249-018-1239-1.

35. Rio E, Drenckhan W, Salonen A, Langevin D. Unusually stable liquid foams. Adv Colloid Interfac. 2014;205:74-86. https:// doi.org/10.1016/j.cis.2013.10.023.

36. Ujhelyi Z, Fenyvesi F, Varadi J, Feher P, Kiss T, Veszelka S, et al. Evaluation of cytotoxicity of surfactants used in self-micro emulsifying drug delivery systems and their effects on paracellular transport in Caco-2 cell monolayer. Eur J Pharm Sci. 2012;47(3):564-73. https://doi.org/10.1016/j.ejps.2012.07.005.

37. Dingemanse J, Soubrouillard C, Paris J, Pisano P, Blin O. Pronounced effect of caprylocaproyl macrogolglycerides on nasal absorption of IS-159, a peptide serotonin 1B/1D-receptor agonist. Clin Pharmacol Ther. 2000;68(2):114-21. https://doi.org/ 10.1067/mcp.2000.108196. 
38. Drenckhan W, Saint-Jalmes A. The science of foaming. Adv Colloid Interfac. 2015;222:228-59. https://doi.org/10.1016/ j.cis.2015.04.001.

39. Severino P, Pinho SC, Souto EB, Santana MH. Polymorphism, crystallinity and hydrophilic-lipophilic balance of stearic acid and stearic acid-capric/caprylic triglyceride matrices for production of stable nanoparticles. Colloids Surf B Biointerfaces. 2011;86(1):125-30. https://doi.org/10.1016/j.colsurfb.2011.03.029.

40. Vasvari G, Kalmar J, Veres P, Vecsernyes M, Bacskay I, Feher P, et al. Matrix systems for oral drug delivery: formulations and drug release. Drug discovery today Technologies. 2018;27:7180. https://doi.org/10.1016/j.ddtec.2018.06.009.

41. Fameau AL, Ventureira J, Novales B, Douliez JP. Foaming and emulsifying properties of fatty acids neutralized by tetrabutylammonium hydroxide. Colloid Surface A. 2012;403:87-95. https://doi.org/10.1016/j.colsurfa.2012.03.059.

42. Stearic Acid. In: Rowe RC, Sheskey PJ, Quinn ME, editors. Handbook of pharmaceutical excipients 6th Edition. USA: Pharmaceutical Press and American Pharmacists Association 2009. p. 697-699.

43. Thakur RK, Vial C, Djelveh G. Combined effects of process, parameters and composition on foaming of dairy emulsions at low temperature in an agitated column. J Food Eng.
$2005 ; 68(3): 335-47$. https://doi.org/10.1016/ j.jfoodeng.2004.06.008.

44. Allen KE, Dickinson E, Murray B. Acidified sodium caseinate emulsion foams containing liquid fat: a comparison with whipped cream. Lwt-Food Sci Technol. 2006;39(3):225-34. https://doi.org/10.1016/j.lwt.2005.02.004.

45. Yalkowsky SH, He Y, Jain P. Handbook of aqueous solubility data. 2nd ed. Boca Raton, FL: CRC Press; 2010.

46. O'Hara T, Dunne A, Butler J, Devane J. A review of methods used to compare dissolution profile data. Pharm Sci Technol To. 1998;1(5):214-23. https://doi.org/10.1016/S1461-5347(98)00053-4.

47. Cunha TA, Serpa RC, de Oliveira APM, Nasser LN, de Freitas LAP, Taveira SF, et al. Effect of stearic acid on enalapril stability and dissolution from multiparticulate solid dosage forms. AAPS PharmSciTech. 2013;14(3):1150-7. https://doi.org/ 10.1208/s12249-013-0006-6.

Publisher's Note Springer Nature remains neutral with regard to jurisdictional claims in published maps and institutional affiliations. 